\title{
GOLD THERAPY IN RHEUMATOID ARTHRITIS.
}

\author{
By PHILIP ELLMAN, M.D., M.R.C.P. \\ (Physician to the St. John Clinic and Institute of Physical Medicine, Consultant Physician to \\ the Rheumatic Unit, St. Stephen's Hospital, London County Council, and to the Harts \\ Sanatorium and Chest Clinic, County Borough of East Ham) \\ and \\ J. S. LAWRENCE, M.D. \\ (Late Medical Registrar, St. John Clinic and Institute of Physical Medicine.)
}

The well recognised clinical results of gold salt therapy in selected cases of pulmonary tuberculosis have justified the assumption of Forestier that it may prove to be beneficial in an allied infective disease with somewhat analogous constitutional and local manifestations, namely rheumatoid arthritis. Many papers have appeared recently on the gold treatment of rheumatoid arthritis and in some of these the results of treating large series of cases have been recorded.

During the past four years we have been treating a large number of cases of rheumatoid arthritis with gold salt therapy. A fuller and more detailed account of this work appears in the College of Physicians Report on the Rheumatic Diseases, Volume IV, edited by C. W. Buckley, and a brief practical summarised account is given in this paper by courtesy of Dr. Buckley.

Although many authors claim a certain proportion of cures as a result of this treatment, there still seems to be some doubt in the minds of many as to what proportion of these cures is due to the effect of the gold and how many would have subsided even without treatment. In order to elucidate this point we have carefully selected 60 cases which we considered typical in every way of the rheumatoid type of arthritis and we have divided them into three equal groups. The first group, which was used as a control, was given injections of oleum amygdale dulcis. This is an oil frequently used for suspending gold preparations. The second group was given injections of Solganol B Oleosum, using a maximum dose of $0 . I$ gms. and the third group was given the same preparation with a maximum dose of 0.2 gms. Although these numbers are comparatively small they have been carefully selected from a large number of cases, have all had a similar amount of physical treatment after which they have reached a standstill, and we have therefore regarded them as representative cases. It is obvious that in view of this careful selection of cases the number available for the experiment has been considerably reduced but we consider that there is corresponding strength in such selected, although limited numbers.

\section{History.}

Although gold compounds have been used for some time and in a variety of diseases, especially pulmonary tuberculosis, it was not until I927 that their use in arthritis was first suggested by Umber. In I929 both Umber and Forestier published works on the treatment of a series of cases by this method. In the series of 24 cases of infective arthritis reported by Feldt (I930), eighteen (75 per cent.) 
were definitely better after treatment with Solganol. Forestier (I932) stated that $\frac{2}{0}$ 70 per cent. of his cases reacted favourably but of those treated within one year $c$ of the onset of the disease Ioo per cent. were improved and 60 per cent. cured. $\overrightarrow{\bar{B}}$ In Huhn's (I930) series of twenty-two cases of infective arthritis 62 per cent. showed increased mobility after treatment with gold. Secher (I932) reported that 24 per cent. of his twenty-three cases were cured and a further 70 per cent. improved. All Slot and Deville's (I934) cases were improved and 87 per cent. of Pemberton's (I935), I7 per cent. of the latter being cured. Crosby (I936) reported improvement in 85 per cent. and Copeman and Tegner (I937) in 94 per cent. $\overrightarrow{0}$ The largest series of cases so far recorded appears to be that of Hartfall, Garland and Goldie (1937). This concerned 690 cases of rheumatoid arthritis treated with four different preparations of gold. 9.9 per cent. were cured, 56.8 per cent. showed marked improvement, I3 per cent. moderate improvement and 6.2 per cent. slight improvement.

\section{Results.*}

We have classified as cured all those cases in which the pain and periarticular swelling have completely disappeared, i.e. in which the joint disease has become inactive. In the long-standing cases-and many of our cases have had treatment for a period of many years - there was of course a residuum of ankylosis and deformity after all pain and swelling had disappeared, so that the term cure is not strictly accurate, but it serves to differentiate those cases in which the gold has produced the maximum possible effect. The cases classified as improved are all those in which the pain, though diminished at the end of treatment, has not completely disappeared.

\section{TABLE I.}

The result at the end of nine months' observation in control cases and those treated with small and large doses of gold, respectively:-

\begin{tabular}{|c|c|c|c|c|c|c|}
\hline & & Cured & Improved & Unaltered & Worse & TOTAL \\
\hline Control & $\cdots$ & . & 13 & 6 & 0 & 20 \\
\hline Gold (Small Dose) & .. & .. & 12 & 1 & 1 & 20 \\
\hline Gold (Large Dose) & . & .. 10 & 9 & 1 & 0 & 20 \\
\hline
\end{tabular}

From this table it can be seen that, whereas the disease has become inactive in one ( 5 per cent.) control case, six (30 per cent.) of those having small doses of gold and ten (50 per cent.) of those having the larger doses have achieved this result. The percentage of cures is somewhat higher than that recorded by certain other observers but this may possibly be due to our scheme of dosage †which is more continuous than is usually employed. In group II, for example, we kept on with the dose of 0.1 gms. of Solganol B till the sedimentation rate reached normal limits, in many cases throughout the whole nine months of our observations. Bach

*This paper is based on work submitted by one of us (J. L.) for a thesis for the M.D. of the University of Edinburgh.

+ We believe that in addition to a complete absence of clinical signs of activity the sedimentation rate should have dropped to normal figures and have remained normal for several months. If this is not the case a further course, or courses, of gold salt therapy will be necessary until such time as this occurs, just as treatment in syphilis is not discontinued despite the absence of activity, until the Wassermann reaction is negative. 
(1936) whose dosage is similar to that employed in our third group (maximum 0.2 gms. weekly) records a similar result. He states that the disease was arrested in half his cases. The personal factor in assessing cure must also be considered in comparing the percentage of cures obtained by different observers.

Table II shows the result of our observations on joint swelling in the three groups of cases. It has been found practicable to take accurate measurements in the case of the interphalangeal, and metacarpo-phalangeal joints, wrists, elbows and knees.

TABLE II.

The changes in joint swelling observed at the end of nine months in control cases and those treated with small and large doses of gold, respectively :-

Wrists and

Interphalangeal metacarpo-phalangeal Knees

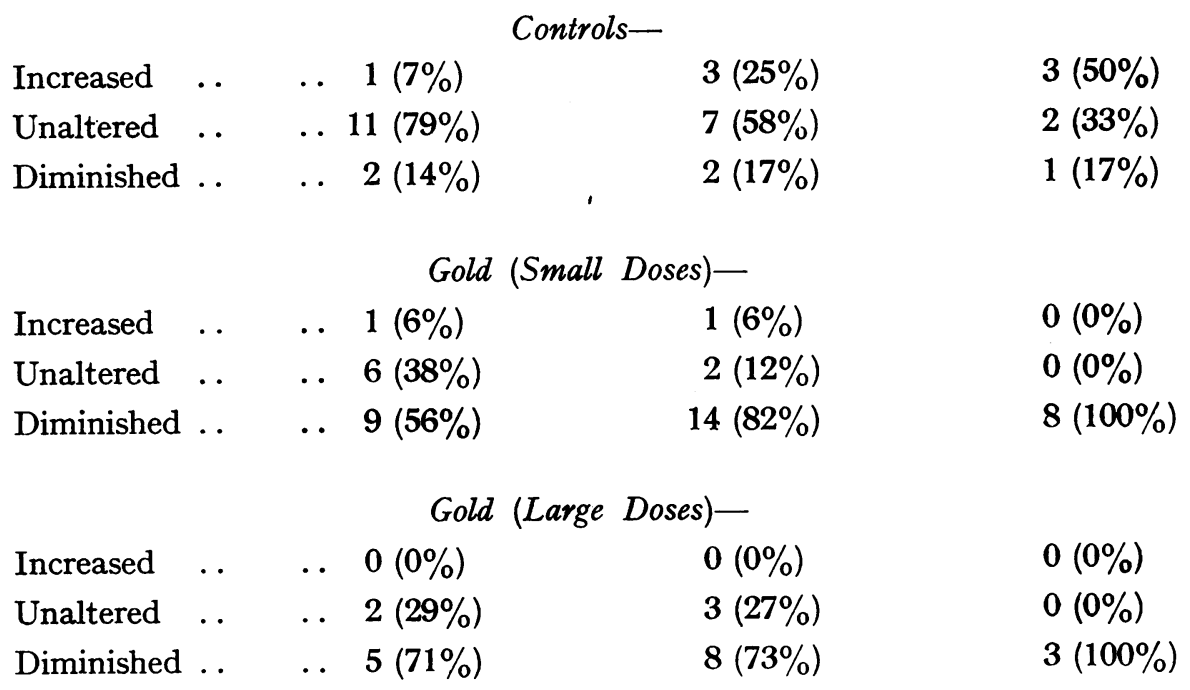

We were surprised, on studying our results, to find how small had been the changes in joint swelling in the control cases. As can be seen from the table, the majority of the measurements in these patients are the same at the completion of the nine months observation period as they were at the beginning. Of the swollen interphalangeal joints, I4 per cent. were diminished in the control group, 56 per cent. were diminished in the small dose group, and $7 \mathrm{I}$ per cent. in the large dose group. Similarly in the case of the swollen metacarpo-phalangeal and wrist joints the percentage in which reduction has occurred is 17,82 and 73 respectively. For the knee joints the figures are I7 per cent., Ioo per cent., and Ioo per cent. These points are further brought out in the graphs. Figure $I$ is a composite graph representing the average alterations calculated from measurements of all the swollen interphalangeal joints. 


\section{FIGURE I.}

Changes in periarticular swelling (interphalangeal joints).

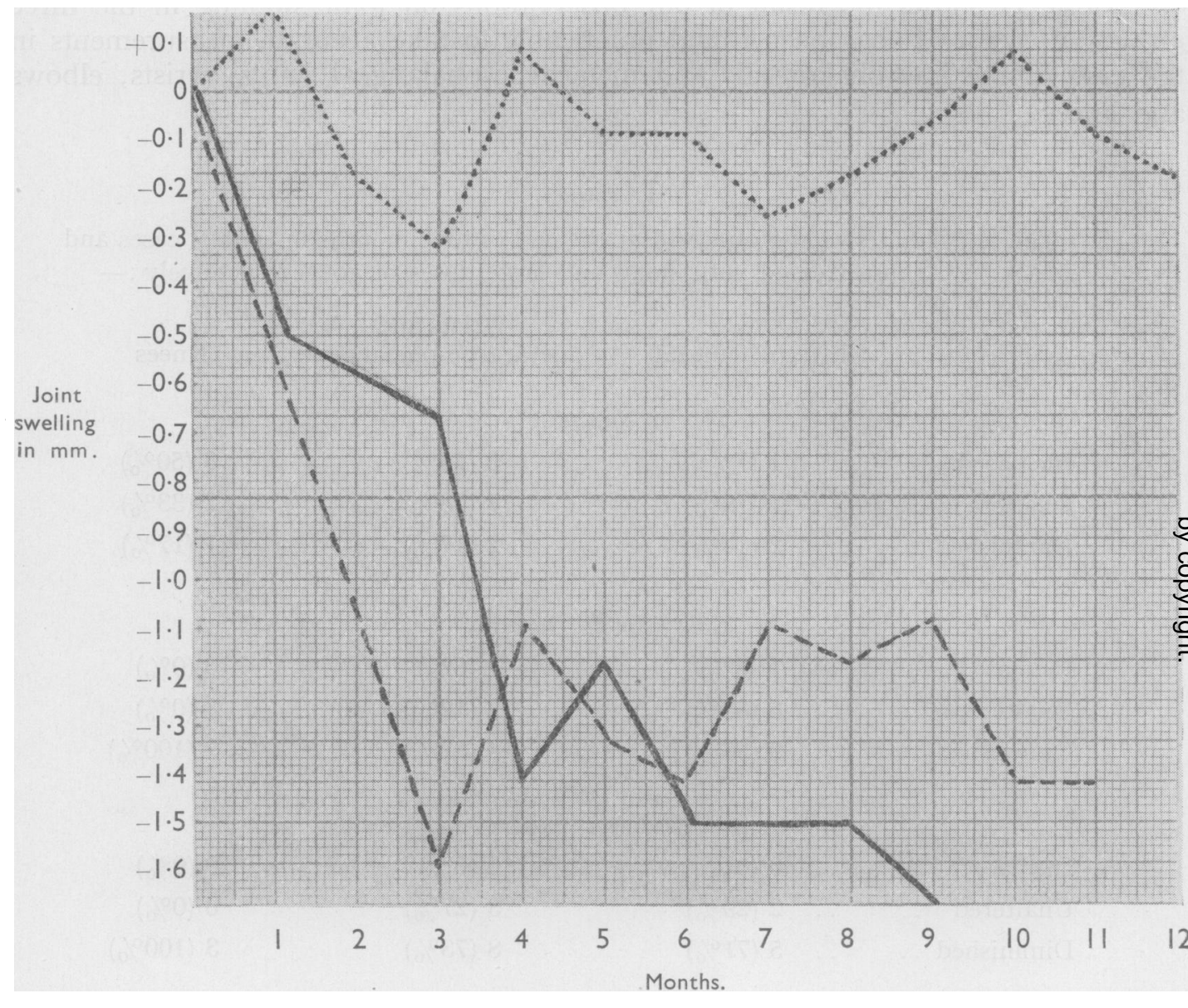

Dotted line-controls.

Broken line-gold, small dosage.

Continuous line-gold, large dosage.

It can be seen from this figure that in the controls (dotted line) there is no appreciable alteration in joint swelling, but in the two gold groups there is a rapid reduction of the swelling especially during the first 3 or 4 months. Figure II. similarly shows the changes in the metacarpo-phalangeal and wrist joints. 
FiguRE II.

Changes in periarticular swelling (metacarpo-phalangeal and wrist joints).

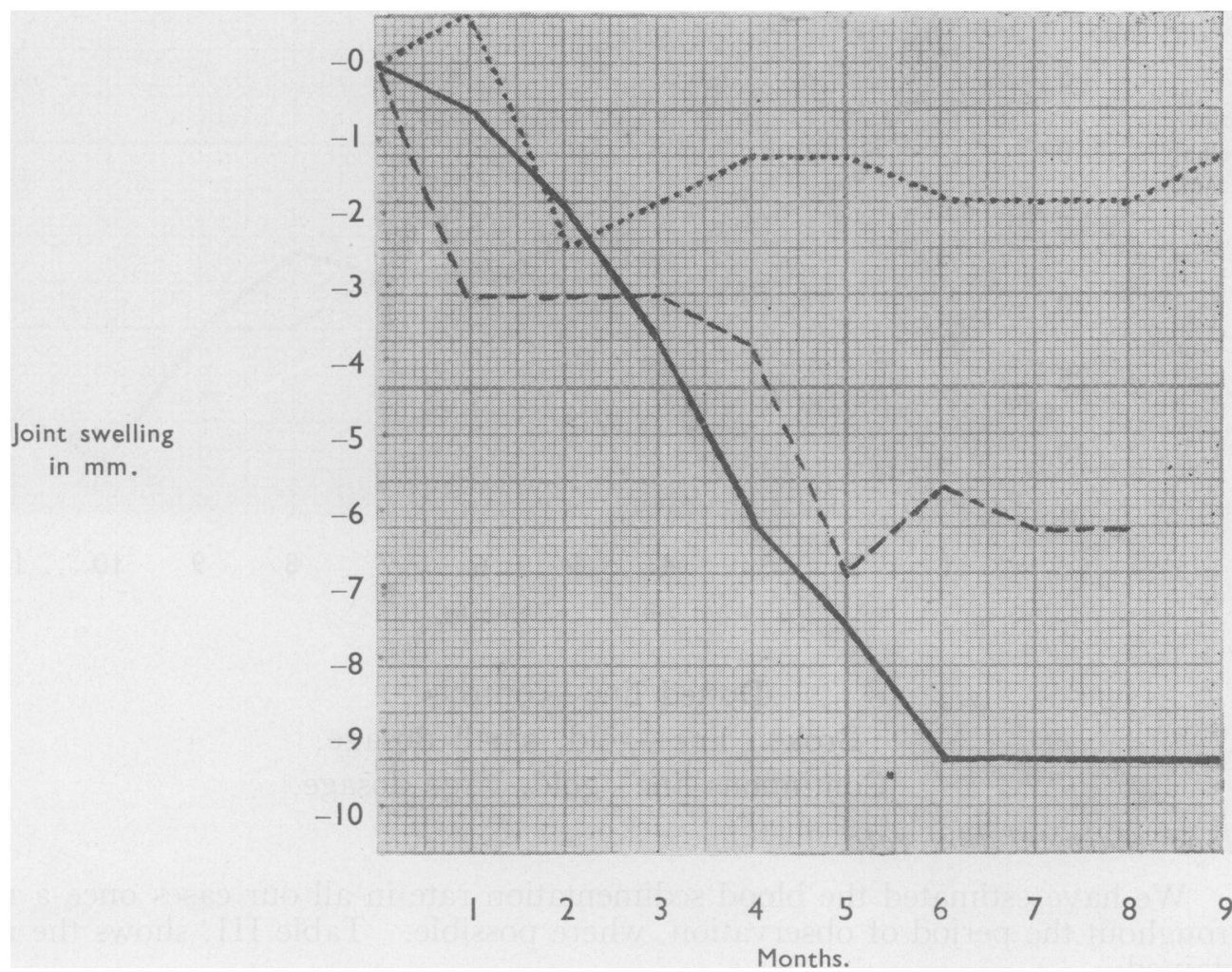

Dotted line-controls.

Broken line-gold, small dosage.

Continuous line-gold, large dosage.

Here again there is the absence of appreciable effect in the controls. There is, however, a much more marked effect in the group having large doses of gold than in the small dose group. Figure III. shows that in the knees also, the changes are similar, there being no marked change in the control group, but a definite reduction in swelling in the two gold groups. 
FIGURE III.

Changes in periarticular swelling (knee joints).

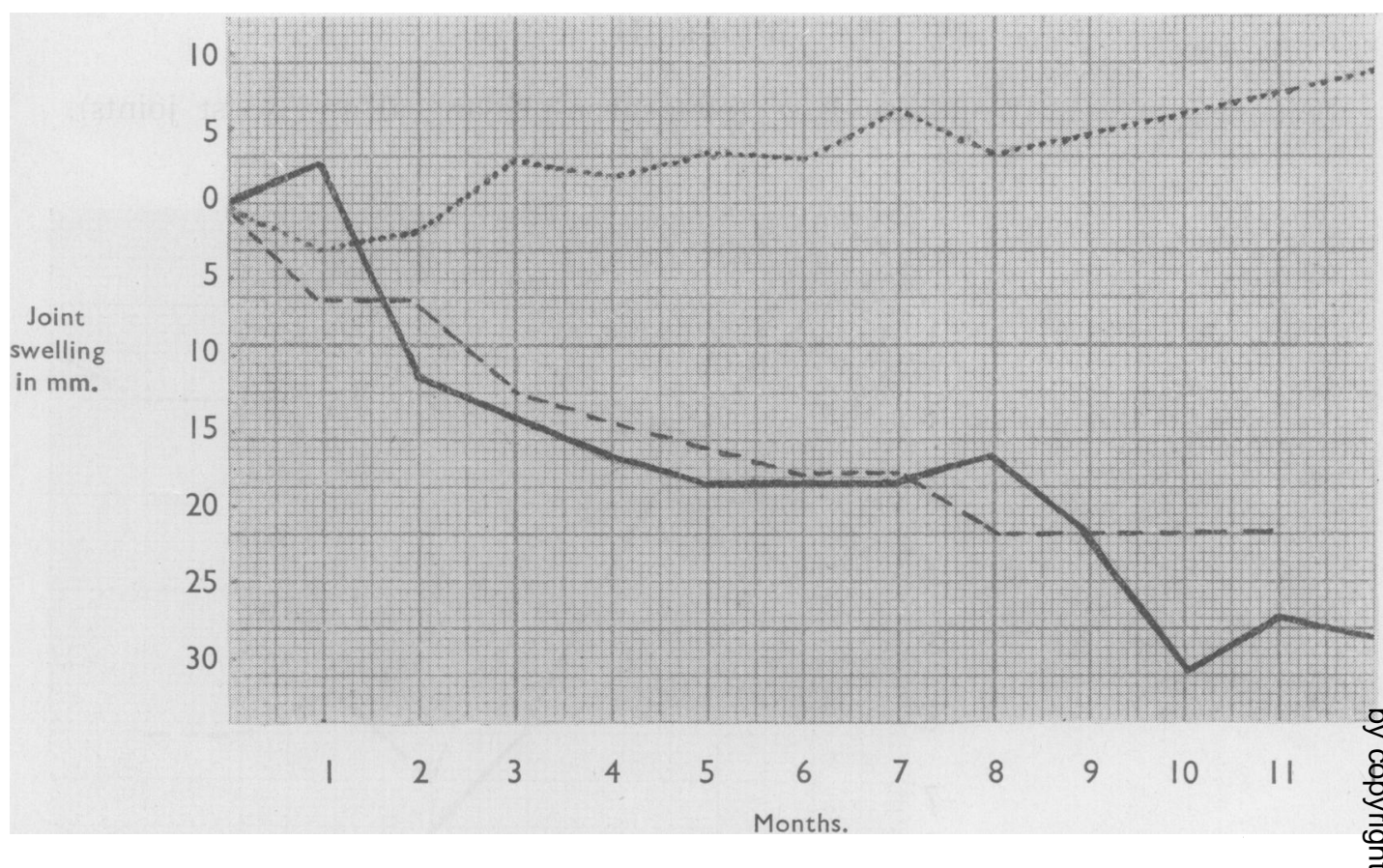

Dotted line-controls.

Broken line--gold, small dosage.

Continuous line-gold, large dosage.

Blood sedimentation rate.

We have estimated the blood sedimentation rate in all our cases once a month throughout the period of observation, where possible. Table III. shows the results obtained.

TABLE III.

The blood sedimentation rate (Westergren method-first hour readings) :Months : 0 1st 2nd 3rd 4th 5th 6th 7th 8th 9th Controls-

\begin{tabular}{|c|c|c|c|c|c|c|c|c|c|}
\hline Case A & 47 & 43 & 40 & 26 & 20 & 32 & 21 & 37 & 40 \\
\hline & 55 & 47 & 36 & 34 & 28 & 36 & 26 & 37 & 29 \\
\hline$\because \mathrm{C}$ & 15 & 11 & 10 & 12 & 23 & 33 & 16 & 19 & 23 \\
\hline D & 28 & 26 & 12 & 14 & 15 & 11 & 20 & 18 & 38 \\
\hline$\Rightarrow \quad$ E & 17 & 14 & 10 & 13 & 19 & 22 & 16 & 13 & 13 \\
\hline $\mathrm{F}$ & 32 & 22 & 32 & 26 & 32 & 30 & 25 & 30 & 29 \\
\hline G & 24 & 30 & 26 & 14 & 24 & 29 & 23 & 29 & 28 \\
\hline$", \quad \mathrm{H}$ & 10 & 16 & 45 & 30 & 18 & 16 & 16 & 20 & 21 \\
\hline$", \quad I$ & 9 & 10 & 9 & 13 & 13 & 1.0 & 10 & 16 & 10 \\
\hline $\mathrm{J}$ & 9 & 10 & 9 & 3 & 4 & 4 & 6 & 3 & 2 \\
\hline $\mathrm{K}$ & 34 & 9 & 11 & 12 & 6 & - & - & - & 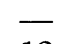 \\
\hline L & 13 & 15 & 14 & 10 & 11 & 9 & 11 & 9 & 12 \\
\hline
\end{tabular}


TABle III (continued).

Months : 0 1st 2nd 3rd 4th 5th 6th 7th 8th 9th

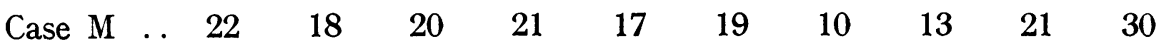

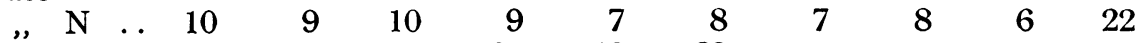

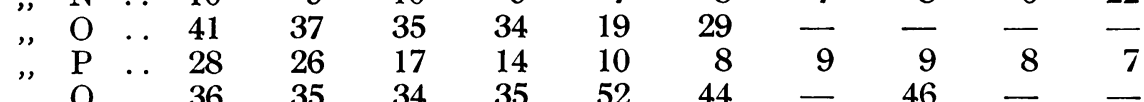

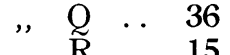

$\begin{array}{rrr}35 & 34 & 35 \\ 10 & 11 & 7\end{array}$ $\begin{array}{llr}16 & 16 & 18\end{array}$ 10 44

", S .. 18 $29 \quad 25$

\section{Gold (Small Doses)-}

\begin{tabular}{|c|c|c|c|c|c|c|c|c|c|c|}
\hline Case & $20 a$. & 45 & 53 & 20 & 31 & 30 & 25 & 30 & 24 & 30 \\
\hline , & 21 & 23 & 16 & 19 & 11 & 5 & 7 & 19 & 8 & 7 \\
\hline & 22 & 25 & 14 & 9 & 59 & 13 & 11 & 28 & 23 & 14 \\
\hline & 23 & 36 & 44 & 42 & 28 & 18 & 20 & 17 & 12 & 36 \\
\hline ," & 24 & 51 & 54 & 62 & 34 & 36 & 21 & 27 & 27 & 28 \\
\hline & 25 & 39 & 26 & 20 & 25 & 22 & 21 & 13 & 15 & 18 \\
\hline ," & 26 & 49 & 31 & 12 & 8 & 7 & 9 & 8 & 10 & 7 \\
\hline ," & 27 & 18 & 16 & 16 & 6 & 8 & 5 & 6 & $\vec{F}$ & - \\
\hline & 28 & 59 & 60 & 38 & 17 & 25 & 32 & 36 & 40 & - \\
\hline ,", & 29 & 11 & 8 & 8 & 8 & 7 & 7 & 9 & 6 & 8 \\
\hline ," & 30 & 52 & 61 & 29 & 20 & 26 & 26 & - & $\overline{-}$ & 31 \\
\hline ," & 31 & 16 & 19 & 6 & 6 & 8 & $11^{\circ}$ & 8 & 12 & 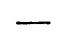 \\
\hline ,, & 32 & 69 & 69 & 69 & 60 & 51 & 49 & 28 & - & - \\
\hline ," & 33 & 47 & 48 & 14 & 9 & 8 & 4 & 6 & 13 & 13 \\
\hline ,. & 34 & 39 & 31 & 27 & 17 & 16 & 6 & 12 & 15 & \\
\hline ,, & 35 & 11 & 9 & 17 & 18 & 16 & 10 & 6 & 5 & 10 \\
\hline & 36 & 37 & 20 & 30 & 33 & 34 & 37 & 36 & 58 & 49 \\
\hline ,, & 37 & 12 & 10 & 9 & 5 & 6 & 5 & 4 & 4 & - \\
\hline & 38 & 37 & 45 & 39 & 43 & 31 & 22 & 23 & 17 & - \\
\hline & 39 & 27 & 20 & 4 & 3 & 4 & - & - & 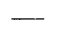 & - \\
\hline ", & $40 \ldots$ & 20 & 11 & 10 & 9 & 10 & 9 & 6 & 7 & 6 \\
\hline
\end{tabular}

$$
\text { Gold (Large Doses)- }
$$

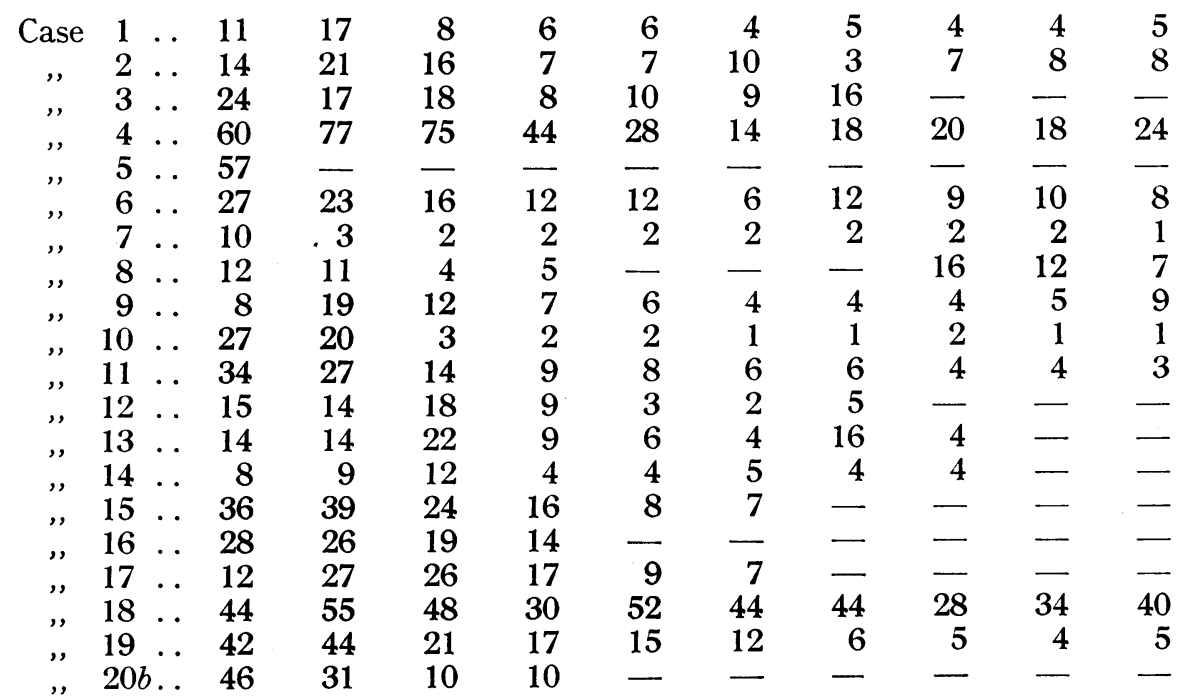


A study of this table shows the marked variations that occur from month to month in the control group. The tendencies are for an alternate rise and fall in the sedimentation rate figures, which sometimes reach normal limits for a month or two and then rise again. In some cases however, the sedimentation rate falls gradually and does not rise again, as for example in case $\mathrm{P}$, where normal limits are reached and maintained. These cases are, however, the exception. In the vast majority there is no marked improvement during the nine month observation period. In actual fact the sedimentation rate is found to have risen by the end of "treatment" in ten cases and fallen in nine, one being unaltered.

In the cases having small doses of gold the tendency for the sedimentation rate to fall during the course of the treatment is much greater. At the end of the nine month period it is less in nineteen, and greater in one. Despite this marked tendency of the sedimentation rate to fall, it is nevertheless possible to make out occasional slight rises, corresponding no doubt to the peaks met with in the control cases.

In one of the cases in the third group it was unfortunately not found possible to obtain a specimen of blood after the first occasion, so that only nineteen cases are available for comparison with the other two groups. Of these eighteen show a fall and one a rise in the sedimentation rate. In the one case which showed a rise, the response was actually considerably better than appears from the table as on the tenth month the figure fell to $3 \mathrm{~mm}$. and was afterwards maintained at this level the patient making a complete recovery. In this group the sedimentation rate fell to normal levels in I4 cases (74 per cent.) as compared with eight (40 per cent.) in the small dose group, and three (I5 per cent.) in the control group.

Figure IV shows in graphic form the course of the three factors so far considered-joint pain, swelling and sedimentation rate in a typical control case.

\section{FIGURE IV.}

The course of joint pain and swelling and sedimentation rate in a typical control case. (Case F.)

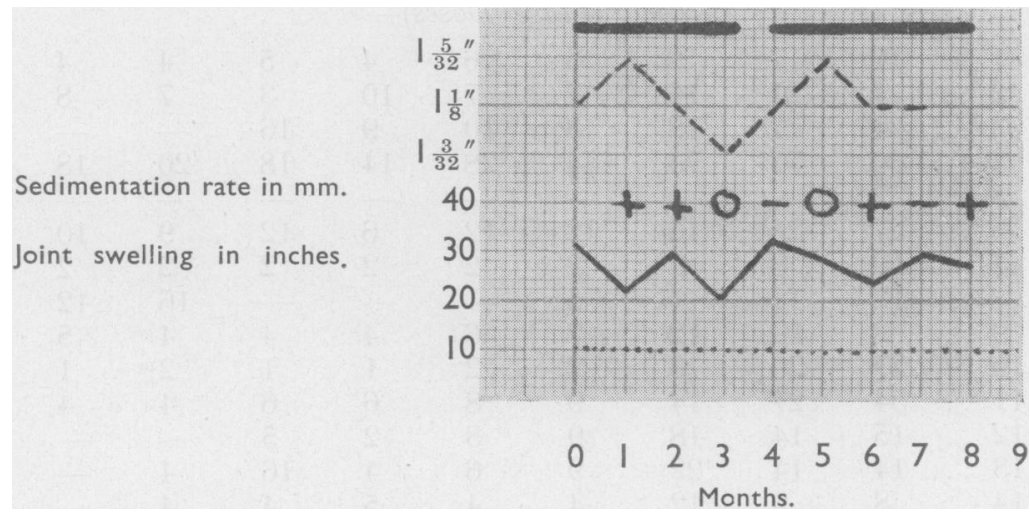

Heavy line-period of "gold" administration.

Broken line-joint swelling.

Continuous line-sedimentation rate.

+ and - -aggravation and amelioration of joint pain. 
It demonstrates the wavy course of the sedimentation rate already referred to. It can be seen that despite these variations there is no final improvement, the sedimentation rate at the end of "treatment" being practically the same as at the beginning. The joint pain and joint swelling also run a variable course, but there is no direct correlation between them. A fall in the sedimentation rate does not accompany a diminution in joint pain or swelling or vice versa. Figure V. and Figure VI. show the course of these same factors in two cases treated with gold in small and large doses respectively.

\section{FIGURE V.}

The course of joint pain and swelling and sedimentation rate in a typical case treated with small doses of gold.

(Case 25.)

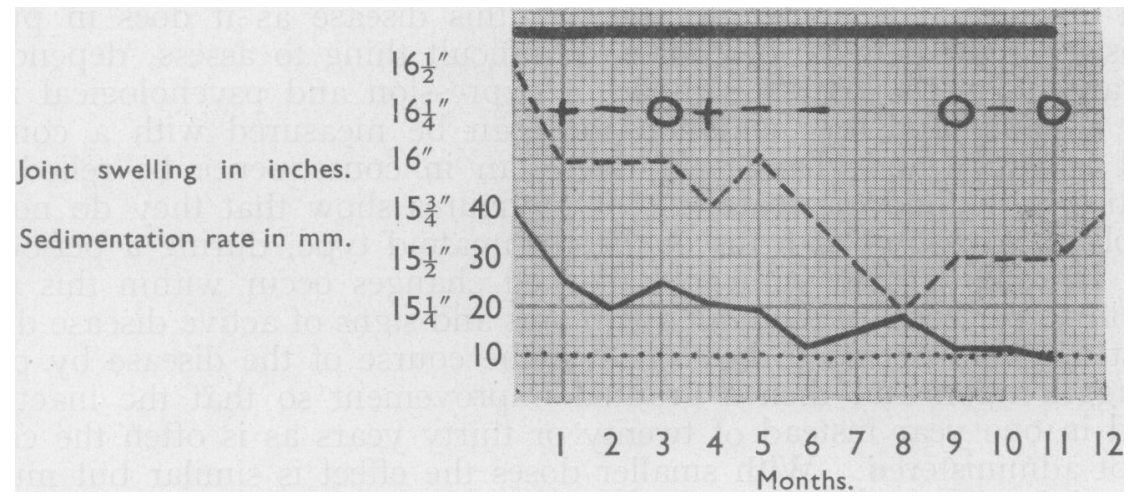

FIGURE VI.

The course of joint pain and swelling and sedimentation rate in a typical case treated with large doses of gold.

(Case II.)

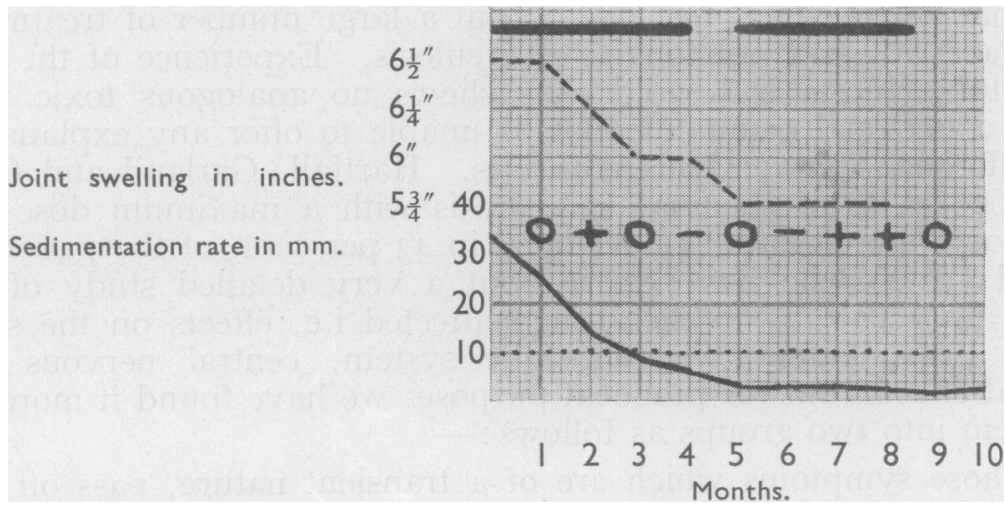

Heavy line-period of "gold" administration.

Broken line-joint swelling.

Continuous line - sedimentation rate.

+ and - -aggravation and amelioration of joint pain. 
In the case treated with small doses of gold there is the gradual fall in the sedimentation rate, as already described, interrupted at intervals by a very mild recrudescence, not however sufficient to prevent the downward trend. The reduction in joint swelling is also interrupted occasionally but there is no direct correlation between them or with the course of the joint pain. The last graph shows the rapid uninterrupted fall of the sedimentation rate which is so often found in cases treated with the larger doses of gold. The joint swelling too shows no increase at any time. Despite this, the joint pain does show occasional aggravations, which, however, were not at any time severe and did not appreciably hinder the considerable improvement occurring at other times.

\section{Discussion.}

Although the number of cases used in this investigation is small, the differences between the gold and control groups is so striking that there can be little doubt that gold does produce a definite effect in this disease as it does in pulmonary tuberculosis. Joint pain is, of course, a difficult thing to assess, depending as it does so largely on the patient's mode of expression and psychological make-up, but joint swelling and sedimentation rate can be measured with a considerable degree of accuracy and changes in them can in consequence be relied upon in investigating a method of treatment. Our figures show that they do not change appreciably in a case of arthritis of the rheumatoid type, during a period of nine months. In cases treated with gold marked changes occur within this period of time and in 50 per cent. of them all symptoms and signs of active disease disappear. The effect of gold appears to be to hasten the course of the disease by producing first an aggravation and then a gradual improvement so that the inactive stage is reached in one year instead of twenty or thirty years as is often the case when gold is not administered. With smaller doses the effect is similar but much more gradual and in the more resistant cases the small dose is not sufficient to bring? about the desired result.

Toxic. Manifestations. An unfortunate feature of the use of gold in the treatment of disease is the frequency with which toxic manifestations arise, as compared, for example, with cases of pulmonary tuberculosis. These appear to be particularly common when the patient is suffering from rheumatoid arthritis, as has been noticed by one of us (P.E.) in carrying out a large number of treatments in both rheumatoid arthritis and pulmonary tuberculosis. Experience of the treatment of pulmonary tuberculosis with gold salts shows no analogous toxic reaction and Forestier in a personal communication is unable to offer any explanation for this apparent difference in two similar diseases. Hartfall, Garland and Goldie (I937) in treating 690 cases of rheumatoid arthritis with a maximum dose of o.I gms. found that toxic manifestations developed in 43 per cent. of the patients. Hinault and Mollard (I934) who have carried out a very detailed study of the matter, divide them up according to the system affected i.e. effects on the skin, mucous membranes, liver, kidneys, hæmopoietic system, central nervous system and psychological effects, but for practical purposes we have found it more satisfactory to divide them into two groups as follows:-

(I) Those symptoms which are of a transient nature, pass off despite continuation of gold therapy, and do not carry any serious prognosis

and

(2) Those symptoms which run a prolonged course, are progressively aggravated if gold therapy is continued, and sometimes endanger the life of the patient. 
In the first group we would place erythemato-papular eruptions, pruritus, herpes labialis, dermatitis herpetiformis, urticaria, Quincke's œdema, albuminuria. These manifestations usually appear early in the course of the treatment and are of an evanescent nature, usually disappearing in a few days to two or three weeks, whether the gold is discontinued or not. In one case we have found the albuminuria persistent, but no signs of impaired kidney function developed.

In the second group we include stomatitis, dermatitis of the squamous or exfoliative type, hepatitis and the blood dyscrasias-purpura hæmorrhagica, agranulocytosis and aplastic anæmia. These occur late in the treatment, towards the end of the first course or during subsequent courses, and tend to be very persistent. They may cause great inconvenience to the patient, as in the case of stomatitis and dermatitis, or give rise to a fatal issue, as in the case of hepatitis and the blood dyscrasias. In Table IV we give details of those toxic manifestations in our present series of cases, which have been sufficiently severe to give rise to definite discomfort to the patient or anxiety to ourselves.

\section{TABLE IV.}

Serious toxic manifestations occurring in our cases:-

$\begin{array}{ccccc}\begin{array}{c}\text { Previous } \\ \text { dose of } \\ \text { gold }\end{array} & \begin{array}{c}\text { Total } \\ \text { amount } \\ \text { of gold }\end{array} & \begin{array}{c}\text { B.S.R. at } \\ \text { time of } \\ \text { onset }\end{array} & \begin{array}{c}\text { B.S.R. before } \\ \text { treatment }\end{array} & \begin{array}{c}\text { Duration } \\ \text { of treatment }\end{array}\end{array}$

Stomatitis-

\begin{tabular}{|c|c|c|c|c|c|}
\hline Case & 0.2 & 1.02 & $8 \mathrm{~mm}$. & $11 \mathrm{~mm}$. & 4 months \\
\hline 2 & 0.2 & 3.36 & 3 & & 7 \\
\hline , 3 & 0.05 & 0.35 & 6 & 16 & 3 \\
\hline 15 & 0.2 & 1.76 & 8, & 36, & 4 \\
\hline
\end{tabular}

Exfoliative Dermatitis-

\begin{tabular}{|c|c|c|c|c|c|c|c|}
\hline Case 12 & 0.2 & 2.11 & $9 \mathrm{~mm}$. & 15 & $\mathrm{~nm}$. & \multicolumn{2}{|c|}{$2 \frac{1}{2}$ months } \\
\hline „, 33 & 0.05 & 1.20 & 4 , & 47 & ", & 6 & ", \\
\hline , 27 & 0.04 & 0.97 & 6 & 18 & ," & 6 & ", \\
\hline , 37 & 0.1 & 0.56 & 9 , & 12 & , & 2 & , \\
\hline , 35 & 0.1 & 2.12 & $10 "$ & 11 & ", & 5 & , \\
\hline , $\quad 39$ & 0.1 & 1.26 & $4 \quad$, & 27 & ", & 4 & , \\
\hline " $\quad \mathrm{Y}$ & 0.2 & 1.66 & 6 & 9 & ", & 3 & ", \\
\hline
\end{tabular}

Agranulocytosis-

$\begin{array}{cccccccc}\text { Case } & 3 & . & 0.2 & 3.31 & 9 \mathrm{~mm} . & 24 \mathrm{~mm} . & 8 \text { months } \\ , & Z & . . & 0.2 & 1.62 & 5, & 12,, & 2 \text {, }\end{array}$

From this it can be seen that, as we have already pointed out this group of toxic manifestations does not occur till the patient has had an appreciable amount of gold. Another noticeable feature is that in those cases in which it arises relatively early, the sedimentation rate at the commencement of treatment was not high, and was in fact but little raised above normal. The most constant feature in all these cases, however is the height of the sedimentation rate just before the 
onset of the toxic effect. In no case was this greater than Io $\mathrm{mm}$. Our patients appeared to be immune to this group of reactions as long as the sedimentation rate remained high, but as soon as it fell to normal figures quite a number of them developed a susceptibility to gold. This susceptibility was so great in some cases that even such minute doses as o.oI gm. were sufficient to bring on a stomatitis, etc., so that treatment had to be abandoned. Latterly we have adopted the plan of continuing with our pre-arranged maximum dose, only till the sedimentation rate has fallen to below II $\mathrm{mm}$. the dose being then reduced to $0.03-0.01$ the last dose being used when it is below $5 \mathrm{~mm}$. We have not had any serious toxic effects since adopting this dosage.

The significance of stomatitis occurring in the course of gold treatment is unfortunately rather difficult to assess, owing to the frequency with which it occurs spontaneously in cases of rheumatoid arthritis. 35 per cent. of our control group suffered from this complication at some time during the period of observation as compared with 43 per cent. of those treated with gold. This is not surprising when it is considered how many of these patients had teeth extracted and dentures fitted shortly after the onset of their disease. A large proportion of the cases of stomatitis occurring in our gold groups were probably of this nature, but the four recorded in Table IV had certain features which distinguished them from the type met with in the control group. The ulcers were more numerous and scattered over a larger area of the mouth and tongue frequently involving the inner surface of the cheeks and the lips, were very persistent, and recurred if gold was resumed shortly afterwards. We have not found these features present in stomatitis associated with ao high sedimentation rate.

The case of agranulocytosis marked $Z$ in the table was not one of the present series but is included as it supports our plea for caution in cases in which the sedimentation rate is low before starting gold treatment. One of these fatal cases has already been recorded by us (Ellman and Lawrence I935). Another case of agranulocytosis in which sedimentation rate figures are available in pulmonary tuberculosis, has been recorded by Brian Taylor (I937). This case, which was not fatal had a sedimentation rate of $25 \mathrm{~mm}$. prior to the onset of the complication. Possibly this may have been a factor in the recovery of the patient.

\section{Conclusion.}

In conclusion we should like to point out that the differences between large and small doses of gold in this series have been recorded after a certain fixed period of time in every case, with the result that the latter have had a smaller total amount of gold than the former. It is our intention, at a later date to give the results of our continued observations on these cases when it will be possible to assess the effect of an identical total dosage in both groups.

\section{Summary.}

I. A series of sixty typical cases of rheumatoid arthritis have been divided into three equal groups - (a) a control group which received injections of almond oil; (b) a group which was treated with small doses of gold, and (c) a group which was treated with large doses of gold.

2. The joint disease was rendered inactive in 5 per cent. of group (a), 30 per cent. of group (b), and 50 per cent. of group (c). 
3. The joint swelling was diminished in $\mathrm{I} 6$ per cent. in group (a), 79 per cent. in group (b), and 8I per cent. in group (c).

4. The sedimentation rate was reduced to normal figures in $I_{5}$ per cent. of group (a), 40 per cent. of group (b), and 74 per cent. of group (c).

5. A simple classification of the toxic manifestations of gold is given, and a method of avoiding the more serious suggested.

We beg to acknowledge our indebtedness to Professor Sir Leonard Hill, and to Sir Frederick Menzies for according facilities for this work. Messrs. Scherings Ltd. have allowed us generous supplies of Solganol B.

REFERENCES.

Bach, F. (1936) St. Bart's Hos. Journ. xliii, 206.

Copeman, W. S. C. and Tegner, W. (1937) Lancet, 1937, 1,554.

Ellman, Philip, Chest Disease in General Practice (Lewis) p. 230.

Ellman, Philip and Lawrence, J. S. (1935) Brit. Med. Journ., 1935, ii, 622

Feldt, A. (1930) Med. Welt., xiii, 437.

Forestier, J. (1929) Bull. Soc. Med. d'Hop de Paris, 1929, 323.

Forestier, J. (1932) Lancet, 1932, 441.

Hartfall, S. J., Garland, H. G. and Goldie, W. (1937) Lancet, 1937, ii. 784

Hinault, U. and Mollard, H. (1934) Le Traitement Aurique de la Tuberculose, Paris, 1934.

Huhn, D. (1930) Zeitschrift fur. Klin. Med. cxxi. 485

Pemberton, H. S. (1935) Lancet, 1935, i, 1,037.

Secher, K. (1932) Ugeskrift g. Laeger., 1932, 44.

Slot, G. and Deville, P. M. (1934) Lancet, 1934, i, 73

Taylor Brian (1937) Lancet, 1937, ii, 73.

Umber, F. (1929) Med. Welt. xviii, 635. 